УДК 608.2

\title{
ЭКСПЕРИМЕНТАЛЬНОЕ ИССЛЕДОВАНИЕ ЭФФЕКТИВНОСТИ ЛАБИРИНТНЫХ УПЛОТНЕНИЙ РОТОРА ГАЗОТУРБИННОГО ДВИГАТЕЛЯ
}

\author{
Графов Вячеслав Игоревич \\ преподаватель \\ Иркутский филиал ФГБОУ ВО \\ «Московский государственный технический \\ университет гражданской авиации»
}

\begin{abstract}
Аннотация. В статье представлены результаты экспериментального исследования эффективности лабиринтных уплотнений ротора газотурбинного двигателя и выработаны методики её повышения.

Выполнено сравнение исследованных моделей и разработана собственная расчетная модель с указанием геометрических размеров.

Ключевые слова: ГТД (газотурбинный двигатель), лабиринтное уплотнение, вихреобразование, протечки, гидравлическое сопротивление.

\section{EXPERIMENTAL STUDY OF THE EFFICIENCY OF LABYRINTH SEALS OF A GAS TURBINE ENGINE ROTOR}

\section{Grafov Vyacheslav Igorevich}

\begin{abstract}
The article presents the results of an experimental study of the efficiency of labyrinth seals of a gas turbine engine rotor and develops methods for improving it.

The comparison of the studied models was performed and a custom calculation model was developed with the indication of geometric dimensions.

Keywords: gas turbine engine, labyrinth seal, vortex formation, leaks, hydraulic resistance.

Опираясь на теоретический материал, проведено экспериментальное исследование с использованием программного газодинамического симулятора Start Flow. Программный комплекс используется для проведения нестационарных газодинамических расчетов, принцип которых основан на численном решении системы уравнений Эйлера.
\end{abstract}


Как выяснилось в результате исследования, основной проблемой лабиринтных уплотнений является недостаточное вихреобразование, и, вследствие этого, не обеспечивается требуемое гидравлическое сопротивление. Это приводит к тому, что масло выбивает в газо-воздушный тракт двигателя, что имеет негативные последствия, так как воздух из двигателя отбирается на самолетные нужды, в частности в систему кондиционирования воздуха и вентиляции, для обеспечения нормальной жизнедеятельности пассажиров при полете на большой высоте. Вторым негативным фактором является то, что утечки масла через лабиринтные уплотнения приводят к недостаточной смазке опор, что в дальнейшем может вызвать масляное голодание и разрушение подшипников, находящихся в опорах.

Для исследование взяты четыре модели (рис. 1) с различной формой профиля гребня, а именно: клиновидная, прямоугольная, трапециевидная и пилообразная. За эталонный образец берем модель с клиновидной формой профиля гребня, а также образец с прямоугольной формой профиля гребня. Это делается с той целью, чтобы на начальном этапе исследовать процессы, протекающие в уплотнениях.

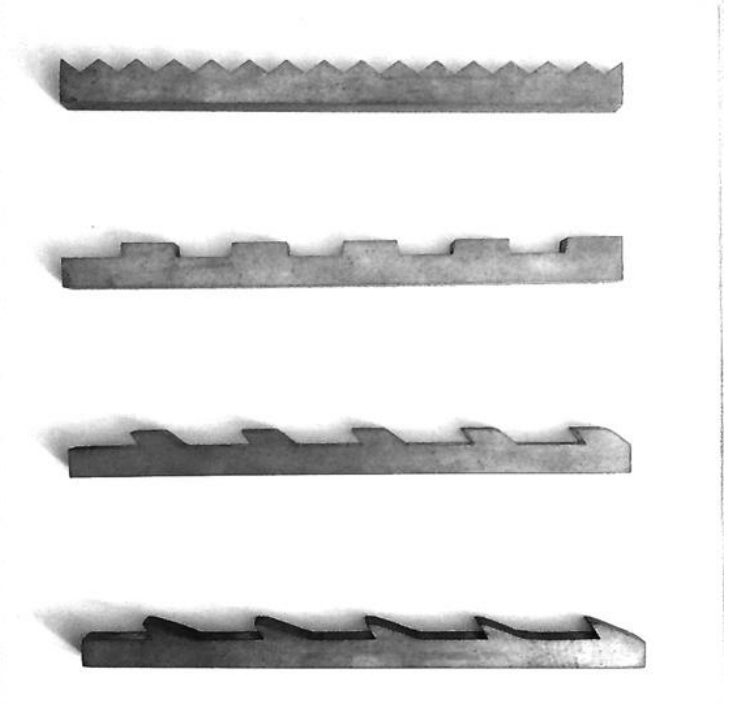

Рис. 1. Экспериментальные модели для исследования

Исследования проводились в несколько этапов. Первый этап аналитический. Он заключается в том, что путем моделирования каждого образца путем наблюдений отследить принцип образования вихрей в уплотнениях, и, имея материалы в области обтекания тел различной формы выявить преимущества и недостатки каждой из моделей. На втором этапе, необходимо произвести замеры основных параметров рабочего процесса и провести сравнение между всеми моделями. Третий этап - 
заключительный. На этом этапе необходимо построить графические зависимости эффективности для каждой из моделей и сделать выводы по результатам исследования. Стоит отметить, что в исследовании принят ряд упрощений, связанных с задаваемыми граничными условиями. Для проведения эксперимента заданы следующие параметры рабочего процесса:

- скорость потока $V-100 \mathrm{M} / \mathrm{c}$;

- температура среды $T-273$ К;

- минимальное давление среды $P_{\min }-101320$ Па.

На начальном этапе в программном комплексе Start Flow создаем модель с одним гребнем, задаем указанные выше граничные условия и запускаем газодинамический расчет. На выходе получаем графическое отображение результатов, представленное на (рис. 2).

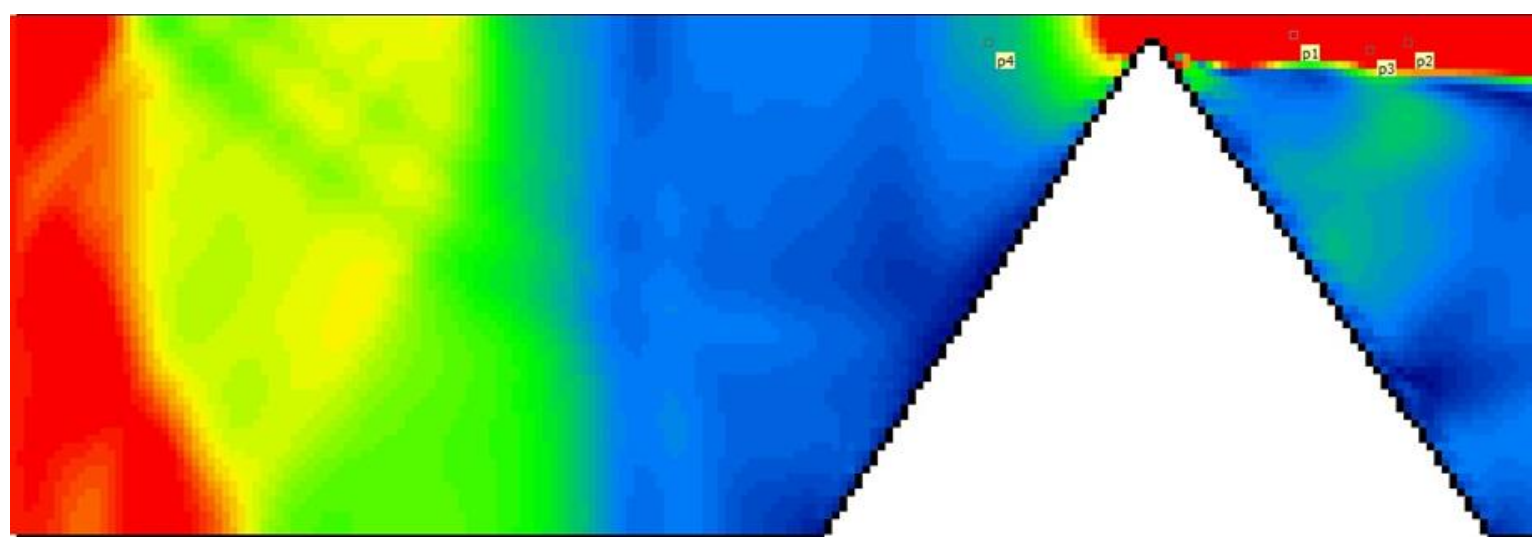

Рис. 2. Графическое отображение обтекания гребня клиновидной формы

Из рис. 2 видно, что применение такой формы профиля гребня даёт не высокую эффективность. Это связано с тем, что на конце гребня образуется кольцевой вихрь, как это показано на рис. 3 [1, с. 45]. В данном случае, стоит отметить, что обеспечивается образование мощного вихря, но при использовании лабиринтного уплотнения с таким гребнем это имеет негативный эффект. На начально этапе набегающий поток тормозится о переднюю кромку, при этом поток постепенно начинает стекать к верхней кромке, образую завихрение. При этом, часть набегающего потока проходит через узкий канал между стенкой и гребнем, увеличивая скорость. Увеличение скорости влечёт за собой уменьшение давления, а, следовательно, уменьшение давления и гидравлического сопротивления. Течение потока на начальном этапе ламинарное. На задней кромке происходит отрыв пограничного слоя, но в полости между стенкой и гребнем течение остается ламинарным. 


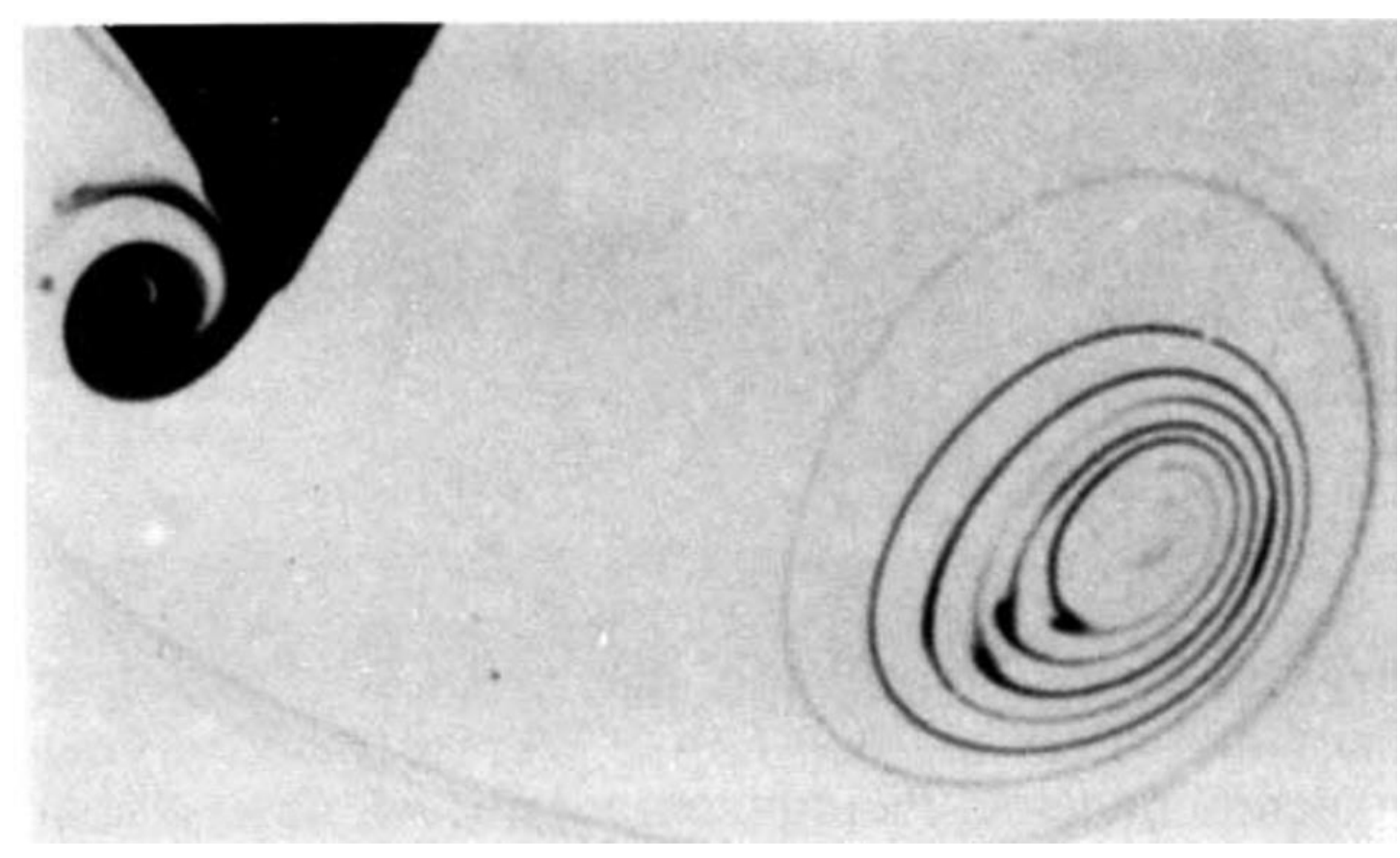

Рис. 3. Формирование кольцевого вихря на клиновидном профиле

Более обширно это наглядно видно на рис. 4. Здесь представлена окончательная картина сформировавшегося вихря. Для большей наглядности изображение представлено с отображение потока с помощью векторов скорости.

Как уже было отмечено, использование такой формы профиля не дает высокой эффективности, но ее наличие необходимо для выявления общей закономерности процессов, протекающих в лабиринтных уплотнениях.

Параметрическая оценка подтвердила невысокую эффективность такого профиля. Так величина давления $p_{1}$ перед гребнями и величина давления $p_{2}$ за гребнями имеет следующие значения:

- гребень 1: $p_{1}=246970$ Па; $p_{2}=26084$ Па. Величина степени повышения давления $\pi_{k}=\frac{p_{1}}{p_{2}}$ составляет 9,4 ;

- гребень 2: $p_{1}=54584$ Па; $p_{2}=9701$ Па. Величина степени повышения давления $\pi_{k}=\frac{p_{1}}{p_{2}}$ составляет 5,6 ;

- гребень 3: $p_{1}=29448$ Па; $p_{2}=9396$ Па. Величина степени повышения давления $\pi_{k}=\frac{p_{1}}{p_{2}}$ составляет 3,13 ;

На рис. 2.6 представлен сводный график основных параметров рабочего процесса (давление, температура и плотность). 


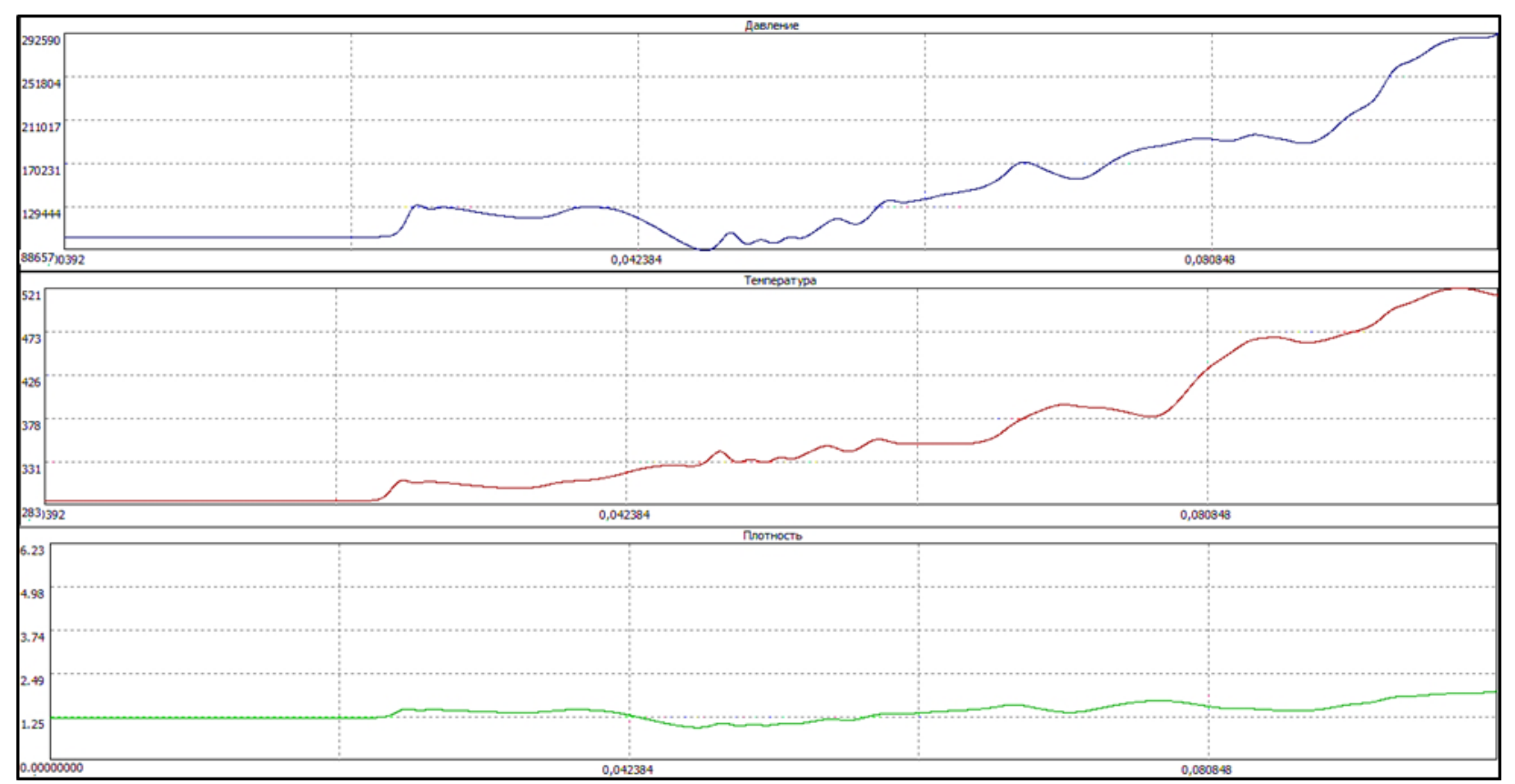

\section{Рис. 4. Сводный график параметров рабочего процесса для образца с клиновидной формой профиля зуба}

На графике видно, что плотность практически не изменяется в течении всего процесса исследования, что говорит о низкой эффективности, при том, что давление увеличивается, но достаточно неравномерно.

Видно, что нагрузка между гребнями распределяется неравномерно, при этом степень повышения давления от гребня к гребню уменьшается, что в очередной раз подтверждает гипотезу о неэффективности клиновидного профиля.

Величина плотности $\rho$ также уменьшается. К тому же, такой профиль испытывает достаточно высокие температурные нагрузки. Максимальная температура достигла своего значения у второго гребня и составила $607 \mathrm{~K}$.

Дальнейшему исследованию подверглась модель с прямоугольной формой профиля гребня. Еще до эксперимента было ясно, что такая модель не даст требуемой эффективности, так как течение при таком профиле ламинарное. В ходе испытания (рис. 5) [1, с. 89] было выявлено наличие двух зон отрыва, имеющих симметричное расположение.

Одна зона расположена впереди выступа, другая за ним. В этих зонах образуются большие рециркуляционные вихри. Также выявлено, что в углах должны существовать последовательности больших и менее слабых вихрей, точно таких, как и в случае с клиновидным профилем. 




\section{Рис. 5. Ползучее течение при обтекании прямоугольного выступа}

Окончательна картина рабочего процесса графически представлена на рис. 6. Для наглядности, изображение представлено с отображением векторов скорости.

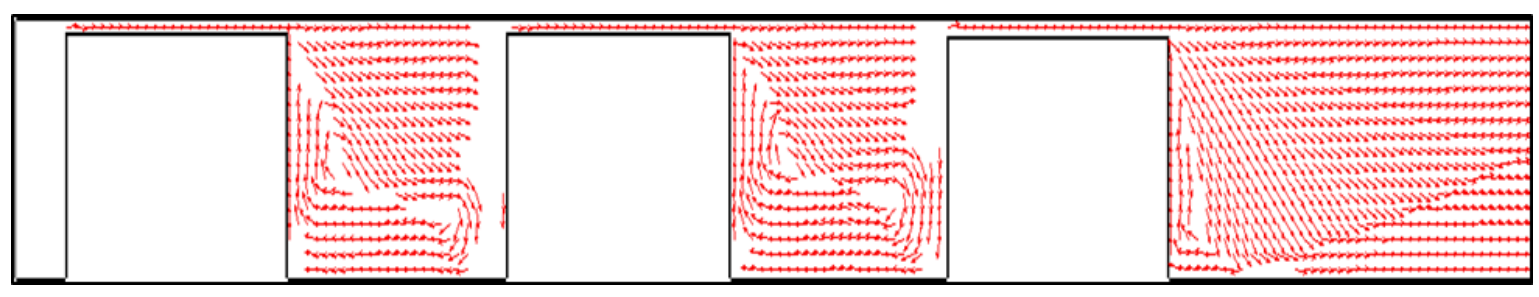

Рис. 6. Графическое отображение векторов скорости при обтекании трех прямоугольных профилей

В ходе численного анализа параметров получены следующие результаты распределений давлений по гребням:

- гребень 1: $p_{1}=11843941$ Па; $p_{2}=952542$ Па. Величина степени повышения давления $\pi_{k}=\frac{p_{1}}{p_{2}}$ составляет 12,4 ;

- гребень 2: $p_{1}=1150060$ Па; $p_{2}=144761$ Па. Величина степени повышения давления $\pi_{k}=\frac{p_{1}}{p_{2}}$ составляет 7,9;

- гребень 3: $p_{1}=464904$ Па; $p_{2}=123433$. Величина степени повышения давления $\pi_{k}=\frac{p_{1}}{p_{2}}$ составляет 3,7 ;

Максимальное значение температуры, при этом, достигло 655 К, что говорит о достаточно высоких температурных нагрузках. Величина плотности $\rho$ как и в случаем с клиновидным профилей от гребня к гребню уменьшается. 
Таким образом, опытном путем выявлена неэффективность применения прямоугольной формы профиля гребня.

На рис. 7 представлен график основных параметров рабочего процесса.

Из рисунка видно, что в целом эффективность такого профиля выше, чем треугольного, но давление и температура распределяются неравномерно, вследствие чего использование такой формы профиля нецелесообразно.

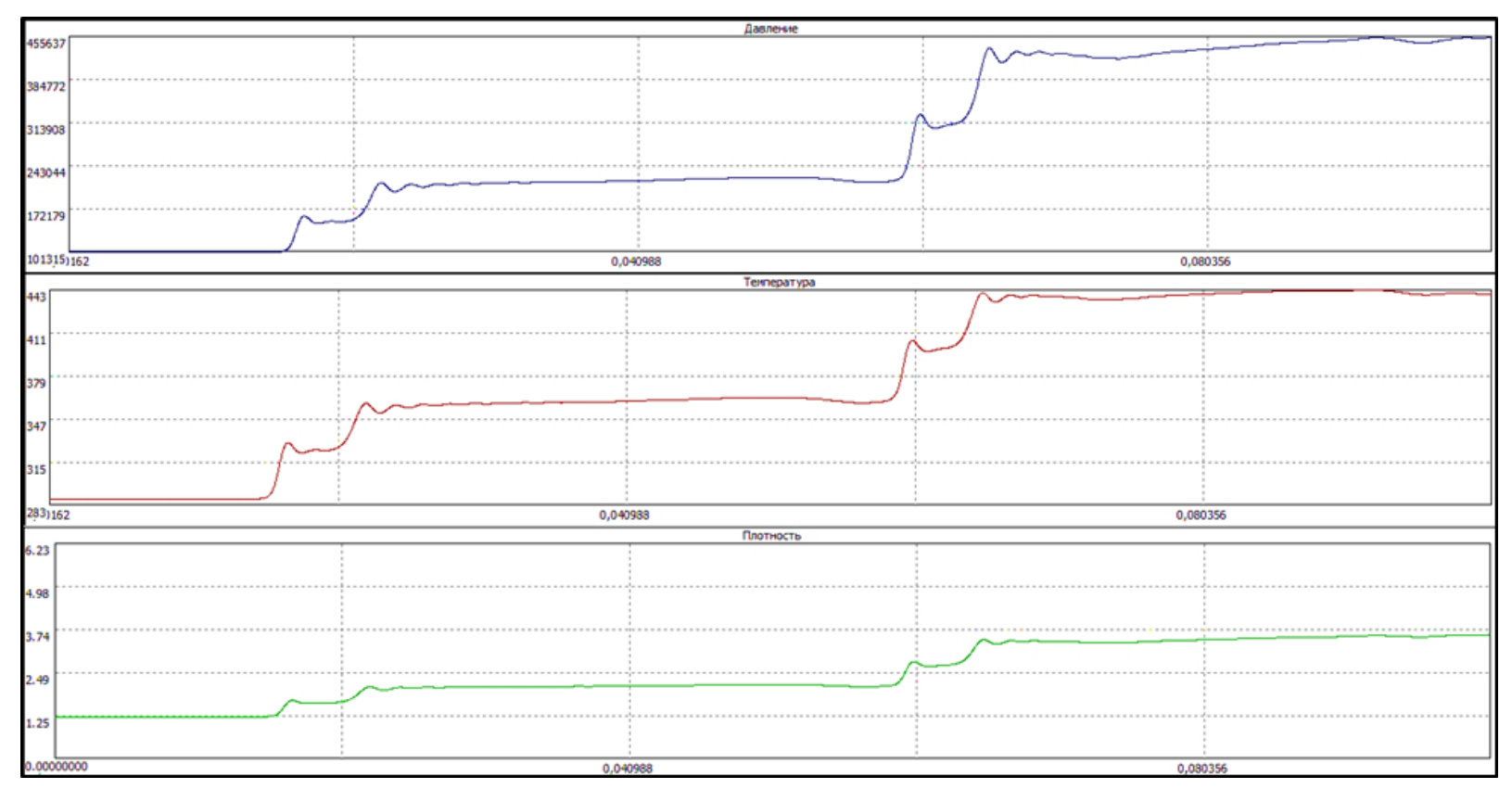

\section{Рис. 7. График параметров рабочего процесса образца с прямоугольной формой профиля гребня}

Стоит отметить, что путем исследования клиновидного и прямоугольного профилей выявлены некоторые пути повышения эффективности. Одним из таких путей является наклон профиля навстречу набегающему потоку. Такой шаг, как предполагается, должен обеспечить создание необходимого гидравлического сопротивления. Также предполагается внедрение конструктивного улучшения, направленного на увеличение степени повышения давления и обеспечения дополнительного вихреобразования.

На рис. 8 представлена экспериментальная модель профиля с трапециевидной формой профиля гребня. Как предполагается, применение такого профиля должно несколько повысить эффективность лабиринтных уплотнений, за счет наклона передней кромки профиля навстречу набегающему потоку.

Из рисунка видно, что рабочий процесс протекает аналогично тем, какие наблюдались при исследовании клиновидного и прямоугольного профилей. В данном случае, передняя кромка наклонена навстречу потоку под некоторым углом. 


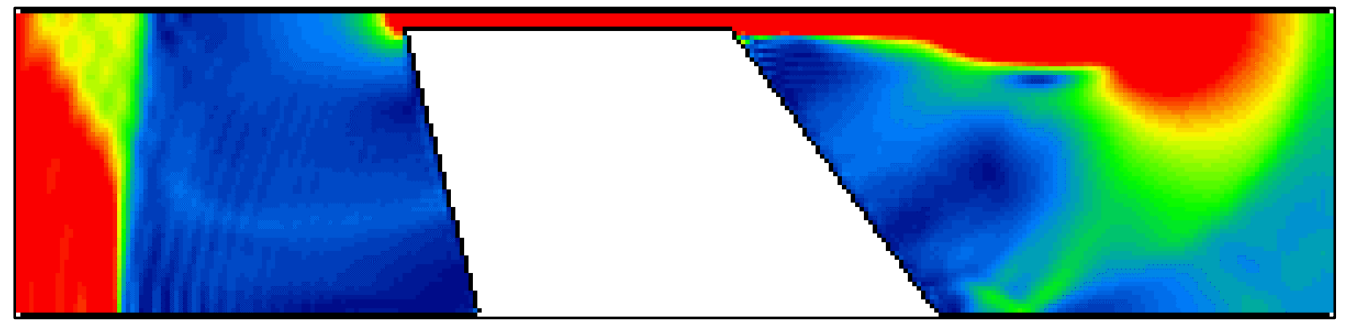

Рис. 8. Экспериментальная модель с трапециевидной формой профиля гребня

Это выполнено для заострения передней кромки профиля, с целью создания дополнительного гидравлического сопротивления. Следует отметить, что в данном случае профиль не симметричный, следовательно, отрыв пограничного слоя также происходит не симметрично. Набегающий поток постепенно стекает с нижней границы кромки к верхней. В верхней части происходит разрыв потока на две части.

Первая часть проходит через узкий канал между профилем и стенкой, а часть поток отталкивается от кромки и далее смешиваясь с набегающим потоком образует циркуляционный вихрь.

Имеющаяся конструкция в полной мере не позволяет достигнуть требуемой эффективности. Для ее увеличения на данном и последующем профиле применим некоторое конструктивное усовершенствование, называемое генератором вихрей. Под генератором вихрей [3, с. 74] будем понимать небольшой хвостовик, выступающей над верхней кромкой профиля на $1-1,5$ мм. Профиль с установленным генератором вихрей представлен на рис. 9.

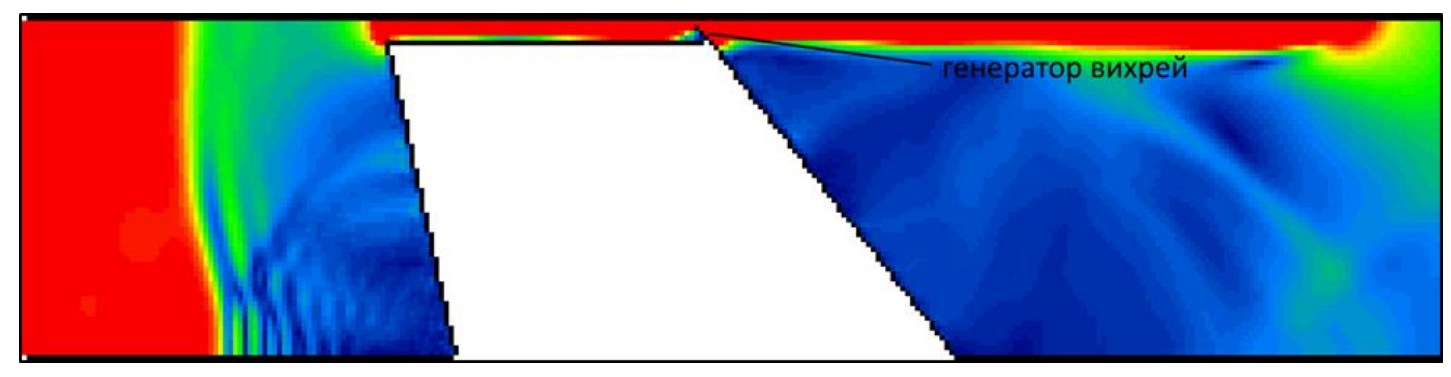

Рис. 9. Экспериментальная модель профиля с использованием генератора вихрей

В самом наименовании устройства заложена основная функция этого устройства, а именно создание дополнительного вихреобразования. В процесс исследования выяснилось, что генератор вихрей также может служить для создания воздушно-масляной эмульсии, тем самым обеспечивая создание требуемого гидравлического сопротивления и создавая подпор. В результате 
анализа экспериментально подтвердилась целесообразность такого улучшения. По сравнению с образцами без установки генератора величина давления возросла более чем на 50\%, а скорость уменьшилась более чем в 1,5 раза.

В дальнейшем для достижения максимальной эффективность, на профиль установлен еще один генератор. Таким образом, между двумя генераторами создается дополнительная уплотнительная полость. Экспериментальная модель такого профиля представлена на рис. 10.



Рис. 10. Экспериментальная модель с установкой двух генераторов вихрей

Как и предполагалось, установка дополнительного генератора повлекло за собой увеличение эффективности. На начальном этапе течение ламинарное, практически плоское. Набегая на генератор, происходит завихрение потока с последующей его турбулезацией. При дальнейшем исследовании выявлено, что установка генераторов целесообразна на каждом гребне, с целью обеспечения равномерного распределения нагрузки по гребням и исключения формирования режимов флутруации, то есть чередования зон вихревого и безвихревого течения. Графически такая модель представлена на рис. 11. Для сравнения под буквой а) профиль без применения генераторов, под б) с их применением.

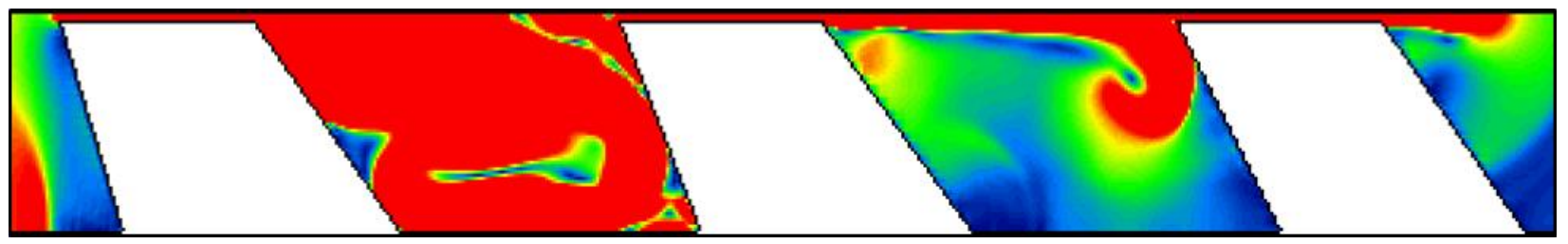

a)



б)

а) без установки генераторов вихрей; б) с установкой генераторов вихрей Рис. 11. Экспериментальные модели профилей 
В таблице 1 представлены численные значения параметров рабочего процесса исследуемого образца.

Таблица 1

Численные результаты основных параметров рабочего процесса

\begin{tabular}{|c|c|c|}
\hline Параметр & Модель без генератора & Модель с генератором \\
\hline$p_{1}($ Па) & 453632 & 849347 \\
\hline$p_{2}($ Па) & 85956 & 46538 \\
\hline$p_{1} / p_{2}$ & 5,27 & 18 \\
\hline$\rho\left(\kappa \Gamma / \mathrm{M}^{3}\right)$ & 3,7 & 6,61 \\
\hline$V(\mathrm{M} / \mathrm{c})$ & 113 & 37 \\
\hline$T_{1}(\mathrm{~K})$ & 426 & 446 \\
\hline$T_{2}(\mathrm{~K})$ & 297 & 295 \\
\hline
\end{tabular}

Наглядно видно, что после установки генераторов вихрей величина протечек уменьшилась более чем в 1,5 раза.

Из таблицы 5 видно, что модель с применением генератора вихрей по всем параметрам эффективнее, чем модель без применения генератора. Величина степени повышения давления возросла более чем в 3 раза. Термодинамические нагрузки уменьшились, по сравнению с треугольным и прямоугольным профилями.

Еще одним перспективным способом повышения эффективности лабиринтных уплотнений, является применение пилообразной формы профиля гребня. Как и трапециевидный профиль, пилообразный имеет некоторый наклон кромок, но под более острым углом. Следует отметить, что рабочий процесс, протекающий в такой модели схож с процессом в трапециевидном профиле.

В данном случае стоит отметить, что в процессе исследования выявилась интересная особенность. Её суть в том, что чрезмерный наклон кромки профиля приводит к незначительному уменьшению эффективности. Это связано с тем, что кромка профиля оказывается слишком заостренной, вследствие чего происходит увеличение скорости потока и как следствие уменьшение давление.

В целом, применение такого профиля позволяет существенно повысить эффективность лабиринтного уплотнения. На рис. 12 представлено окончательное исполнения модели с установкой трех гребней и применением на каждом гребне двух генераторов вихрей. 


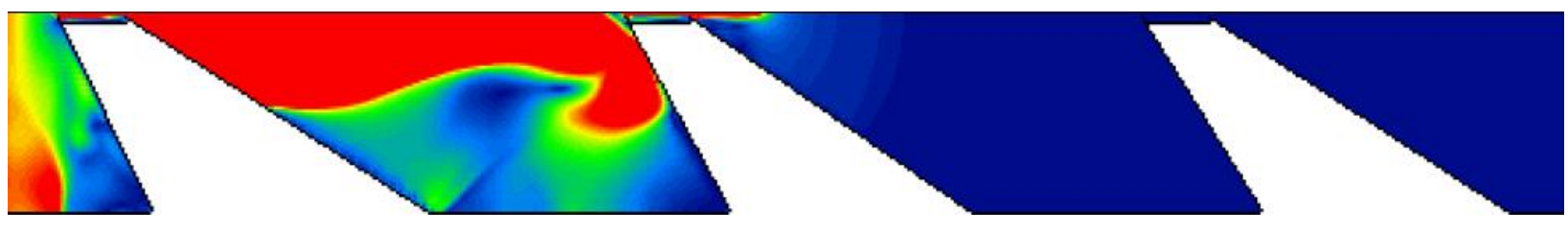

Рис. 12. Экспериментальная модель лабиринтного уплотнения

\section{с применением генераторов вихрей}

Вывод: применение пилообразного профиля имеет несколько меньшую эффективность, по сравнению с трапециевидным. Тем не менее, применение такого профиля гребня в лабиринтных уплотнениях авиационных газотурбинных двигателей целесообразно. На практике подтвердилось, что установка на гребни лабиринтного уплотнения генераторов вихрей приводит к уменьшению протечек, и как следствие ведёт к увеличению эффективности лабиринтных уплотнений.

В результате анализа теоретического материала, а также проведения экспериментальных исследований моделей лабиринтных уплотнений $\mathrm{c}$ использованием программного газодинамического симулятора Start Flow выработаны следующие рекомендации и способы повышения эффективности лабиринтных уплотнений.

1 В результате исследования экспериментальных моделей выяснилось, что наклон передней кромки профиля навстречу набегающему потоку влечёт увеличение эффективности лабиринтных уплотнений;

ПРИМЕЧАНИЕ: исследование профиля пилообразной формы на практике показало, что наклон профиля должен быть заключен в пределах от 70 до $78^{\circ}$. Дальнейшее увеличение угла будет способствовать уменьшению эффективности лабиринтного уплотнения.

2 Уменьшение зазора между гребнем лабиринтного уплотнения и стенкой приводит к увеличению эффективности уплотнений. Величина зазора должна быть в пределах от 0,5 мм до 2,5 мм;

3 Увеличение расстояния между гребнями увеличивает эффективность лабиринтного уплотнения;

4 Количество гребней оказывает существенное влияние на эффективность лабиринтных уплотнений. В ходе экспериментального моделирования, выявлено, что оптимальное количество гребней от 5 до 7. В отдельных случаях число гребней может быть увеличено, но не более 12;

5 Подбор оптимальных значений шага $t$ между гребнями и высоты гребня $h$ повышает эффективность уплотнений; 
6 Наличие винтовой канавки на роторе приводит к некоторому снижению величины протечек через уплотнения;

7 Применение конструктивного улучшения, называемого генератором вихрей. Установка такого устройства существенно повышает эффективность лабиринтного уплотнения.

8 Выявлено неравномерное падение давления по длине уплотнения при любом количестве его гребней, вызванное структурными преобразованиями потока в камерах.

9 Вращение вала приводит к уменьшению протечки через уплотнение тем больше, чем выше окружная скорость, уплотняемый перепад и меньше радиальный зазор.

Моделирование, с учетом анализа теоретического материала и исследований образцов различной формы, позволило подобрать и разработать собственную расчетную модель лабиринтного уплотнения.

Разработанная модель с указанием необходимых геометрических размеров представлена на рис. 13. Предполагается оформление патента на данную модель, с дальнейшим её внедрение в предприятия, занимающиеся двигателестроением.

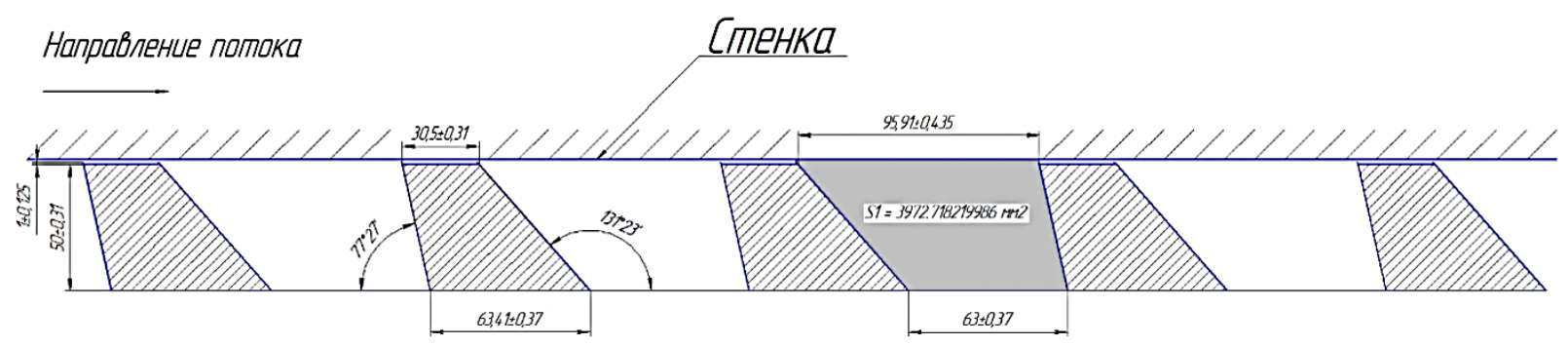

Рис. 13. Предлагаемая модель лабиринтного уплотнения

При создании модели выбрана трапециевидная форма профиля гребня, которая в результате экспериментального исследования показала наибольшую эффективность. На каждом из гребней установлено по два генератора вихрей. Угол наклона передней кромки гребня составляет $77^{\circ}$. Диаметр зазора между торцевой поверхностью генератора вихрей и стенкой составляет $1 \pm 0,125$ мм, при этом высота гребня составляет 1 мм.

Вывод: основным из путей, способствующих повышению эффективности является применение технического усовершенствования, именуемого генератором вихрей. Как было отмечено ранее, установка генератора вихрей приводит к турбулезации пограничного слоя, что в свою очередь влияет на ряд параметров рабочего процесса, таких как, 
гидравлическое сопротивление, величина степени повышения давления и величина протечек (секундно - массовый расход). На практике проведено исследование и представлена собственная модель уплотнения с применением генераторов вихрей, с указанием геометрических размеров.

\section{Список литературы}

1. М. Ван-Дайк. Альбом течений жидкости и газа. - М.: Мир, 1986.

2. Забобин В. В. Теория авиационных двигателей, термогазодинамический расчет двухконтурного турбореактивного двигателя. М.: МГТУ ГА, 2009.

3. Даниленко Н. В., Кривель П. М. Теория авиационных двигателей Иркутск: ИВВАИУ (ВИ), 2006.

(С) В.И. Графов, 2020 